\title{
Risk factors for primary graft dysfunction after lung transplantation
}

\author{
Bryan A. Whitson, MD, Dilip S. Nath, MD, Adam C. Johnson, MD, Adam R. Walker, BS, Matthew E. Prekker, MD, \\ David M. Radosevich, PhD, Cynthia S. Herrington, MD, and Peter S. Dahlberg, MD, PhD
}

From the University of Minnesota, Department of Surgery, Division of Cardiovascular and Thoracic Surgery, Minneapolis, Minn.

Read at the Eighty-fifth Annual Meeting of The American Association for Thoracic Surgery, San Francisco, Calif, April 10-13, 2005.

Received for publication June 14, 2005; revisions accepted Oct 12, 2005; accepted for publication Oct 25, 2005.

Address for reprints: Peter S. Dahlberg, $\mathrm{MD}, \mathrm{PhD}$, University of Minnesota, MMC 207, 420 Delaware St SE, Minneapolis, MN 55455 (E-mail: dahlb002@umn.edu).

J Thorac Cardiovasc Surg 2006;131:73-80

$0022-5223 / \$ 32.00$

Copyright () 2006 by The American Association for Thoracic Surgery

doi:10.1016/j.jtcvs.2005.08.039
Objective: The International Society for Heart and Lung Transplantation has proposed a new grading system for primary graft dysfunction based on the ratio of arterial oxygen to fraction of inspired oxygen measured within 48 hours after lung transplantation. Worsening primary graft dysfunction grade is associated with increased operative mortality rates and decreased long-term survival. This study evaluated donor and recipient risk factors for postoperative International Society for Heart and Lung Transplantation grade 3 primary graft dysfunction.

Methods: We reviewed donor and recipient medical records of 402 consecutive lung transplantations performed between 1992 and 2004. We calculated a worst International Society for Heart and Lung Transplantation primary graft dysfunction grade in the first 48 hours postoperatively. Severe primary graft dysfunction (International Society for Heart and Lung Transplantation grade 3) was defined by a ratio of arterial oxygen to fraction of inspired oxygen of less than 200. Associations of potential risk factors with grade 3 primary graft dysfunction in the first 48 hours postoperatively were examined through bivariate and multivariate analysis.

Results: The 90-day mortality rate associated with the development of International Society for Heart and Lung Transplantation grade 3 primary graft dysfunction in the first 48 hours postoperatively was $17 \%$ versus $9 \%$ in the group without grade 3 primary graft dysfunction. Significant bivariate risk factors associated with this end point were increasing donor age, donor smoking history of more than 10 pack-years, early transplantation era (1992-1998), increasing preoperative recipient pulmonary artery pressure, and recipient diagnosis. In the multivariate analysis only recipient pulmonary artery pressure, donor age, and transplantation era were associated with grade 3 primary graft dysfunction in the first 48 hours postoperatively at a $P$ value of less than .05 .

Conclusions: Our analysis of donor and recipient risk factors for severe primary graft dysfunction identified patient groups at high risk for poor outcomes after lung transplantation that might benefit from treatments aimed at reducing reperfusion injury.

$\mathrm{T}$ Transplantation is the only effective treatment for several end-stage lung diseases. However, the outcomes of patients after a lung transplantation procedure are poor when compared with those after transplantation of other solid organs. Early mortality rates approach $15 \%$ in most series, and 3-year patient survival rates are approximately $50 \%$. Predictors of 90-day mortality, including poor early graft function (ischemia-reperfusion injury or primary graft dysfunction [PGD]), have been identified. ${ }^{1}$ Reported 30 -day mortality rates of patients with severe PGD are nearly 8 times as high as those for patients without severe PGD. ${ }^{2}$ A classification system for PGD based on the measured partial pressure of arterial oxygen to fraction of inspired oxygen ratio (P/F ratio) has recently been proposed 


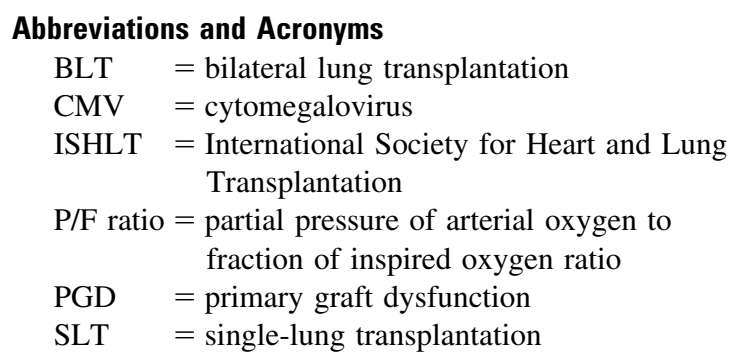

by an International Society for Heart and Lung Transplantation (ISHLT) working group. ${ }^{3}$ It has many features in common with the American European Consensus Conference definition of acute respiratory distress syndrome. ${ }^{4} \mathrm{~Pa}-$ tients with the most severe PGD grade (ISHLT grade 3) have decreased perioperative survival, an increased rate of perioperative complications, and an increased length of hospital stay. ${ }^{1-3}$ Other measures of PGD, such as oxygenation index or lung compliance, might have added prognostic utility, but these have not been validated in reports of large series of patients. ${ }^{5-11}$

The purpose of this study was to identify donor and recipient characteristics that were associated with the development of ISHLT grade 3 PGD in the first 48 hours after lung transplantation.

\section{Methods \\ Patients}

The Institutional Review Board at the University of Minnesota approved this study. Charts of all patients undergoing a lung transplantation procedure from January 1, 1992, through December 31, 2004, were reviewed. Information about the respective donors was also collected. Those patients who underwent living donor lobar transplantation and those who received heart-lung transplants were excluded from analysis. The donor characteristics examined were demographics, cause of death, cytomegalovirus (CMV) exposure, days on the ventilator before retrieval of the organs, bronchoscopic findings, Gram stain and culture results, blood gas analysis, and graft ischemic times. Recipient characteristics examined were demographics, preoperative hemodynamics, comorbidities, CMV status, pulmonary function tests, whether cardiopulmonary bypass was used for the operation, and the preservation solution used for the organs. During the procurement, low tidal volume ventilation was used. Initially, prostaglandin E is administered to donors. Next, the pulmonary arteries are crossclamped and donor lungs are then antegradely perfused. After donor lung implantation, the crossclamps are removed over a 5-minute period. This approach was consistent throughout the series.

\section{Transplant Criteria and Immunosuppression}

The lung transplantation protocol at our institution, including details of organ retrieval, operative technique, and postoperative immunosuppression, has been previously reported. ${ }^{12-14}$ The ma- jority of patients received cyclosporine [INN: ciclosporin], prednisone, and azathioprine; however, the substitution of newer immunosuppressants, such as mycophenolate mofetil and tacrolimus, to the regimen of some recipients took place during the time period under review. Induction therapy was not used in our program during the study period.

At our institution, we have only offered transplantations to patients younger than 65 years of age at the time of their first evaluation. Other relative contraindications include significant concurrent medical illnesses (ie, hepatic disease with portal hypertension or coronary artery disease) that would limit survival, rehabilitation, or both; chronic high-dose steroid use (>20 mg of prednisone per day); and a diagnosis of a rheumatologic disease.

\section{Assignment of ISHLT PGD Grades}

Patients were assigned to PGD grades 1 through 3 on the basis of guidelines issued by a 2004 ISHLT working group conference on the subject (Figure 1). We made 2 changes to the ISHLT grading system for the purposes of our analysis (Table 1). First, the original grading system proposed including a fifth time point for grading PGD severity 72 hours after transplantation (T72). Second, any patient with a $\mathrm{P} / \mathrm{F}$ ratio of greater than 300 was classified as having grade 1 PGD. We did not analyze their chest radiographs for the presence or absence of infiltrates. Time points chosen for analysis were at intensive care unit arrival (T0) and 12 hours (T12), 24 hours (T24), and 48 hours after transplantation (T48). The worst grade at $\mathrm{T}(0-48)$ reflected the most severe grade recorded during the 48-hour period.

Only analysis of the 48-hour worst grade data from our institution showed that the development of modified IHSLT grade 3 PGD was associated with increased perioperative mortality rates and decreased long-term survival (Figure 1, $B$, for perioperative mortality and Figure 2 for long-term survival). ${ }^{15,16}$ As a result of this finding, patients were stratified into 2 primary outcome groups for study: those who did and those who did not have modified ISHLT grade 3 PGD within the first 48 hours after the transplantation. To be placed in the favorable group on the basis of extubation (one of the definition's criteria), the patient had to remain extubated for 48 hours. Patients requiring extracorporeal membrane oxygenation support (23/ 402 [6\%] of patients) were automatically classified as having grade 3 PGD.

\section{Statistical Analysis}

Donor-related and patient-related characteristics were analyzed for their association with the development of modified ISHLT grade 3 PGD within the first 48 hours after transplantation (severe PGD group). These bivariate associations were tested for statistical significance by using either the Pearson $\chi^{2}$ test for nominal and ordinal data or the independent sample $t$ test for continuous variables. Analyses were performed with SAS for Windows, Version 9.1 (SAS Institute Inc, Cary, NC).

Donor and patient characteristics that were statistically significantly related to severe PGD $(P<.100)$ were tested for inclusion in the final multivariate analysis. Multivariate logistic regression was used to adjust for potential confounding. Characteristics were introduced stepwise in the following order: demographic and per- 


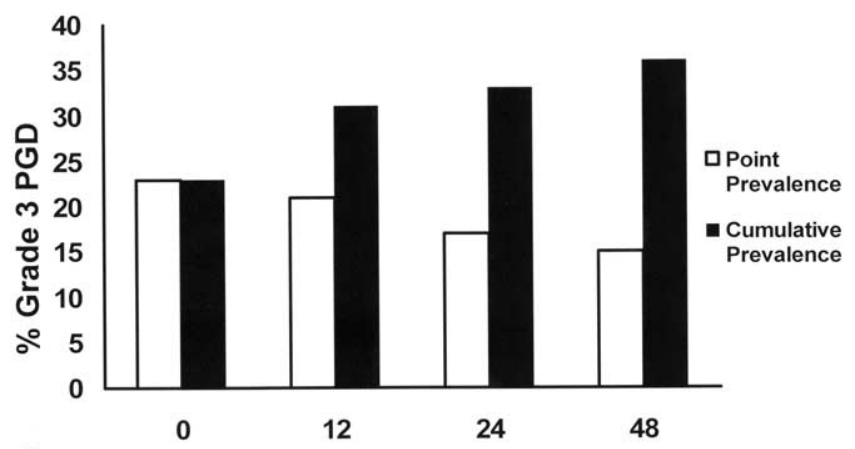

A Hours After Transplant

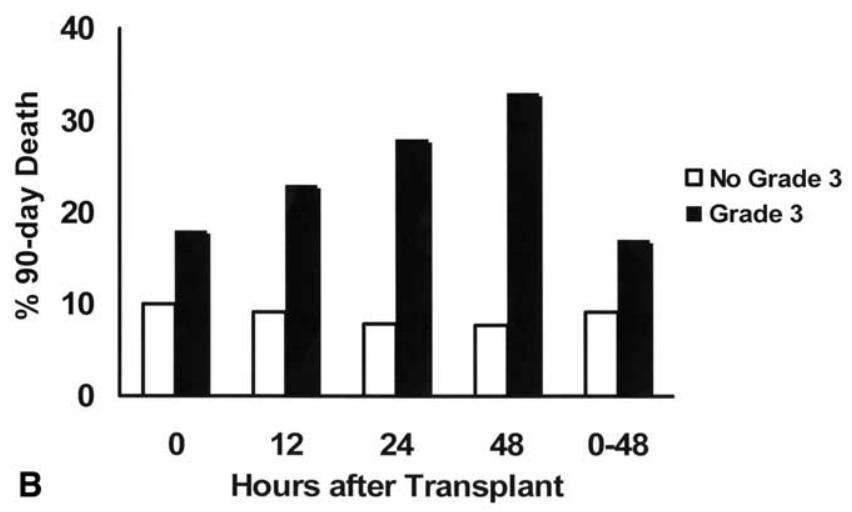

Figure 1. Prevalence and 90-day survival of patients with grade 3 primary graft dysfunction (PGD). A, Point prevalence of International Society for Heart and Lung Transplantation grade 3 PGD at each individual time during the first $\mathbf{4 8}$ hours is represented by the open bars. The cumulative percentage of grade 3 prevalence is shown in the filled bars. B, Percentage of patients dying within 90 days after surgical intervention stratified by whether (filled bars) or not (open bars) the patient had grade 3 PGD at each time point after the operation and as a worst grade 48-hour end point (last set of bars). The differences in 90-day death rates among groups were significantly different $\left(P<.05, \chi^{2}\right.$ test $)$ at all time points.

sonal characteristics, pulmonary arterial pressures/ISHLT grade, and donor characteristics. The final model included donor and patient characteristics that were independently and statistically associated $(P<.05)$ with severe PGD. Final results were expressed as multivariate odds ratios and $95 \%$ confidence intervals. The odds ratios can be interpreted as the increased or decreased odds of grade 3 PGD, with those with the characteristic compared with the odds of the event in those without the characteristic (the reference category). The c-statistic was used to measure the discrimination of the final model. Values approaching 0.70 or greater were considered the minimum necessary for a sound model. The Hosmer-Lemeshow test for goodness of fit was used to measure the calibration of the final model. A statistically nonsignificant $\chi^{2}$ test result is accepted for adequate agreement between the observed and expected events. ${ }^{17}$
TABLE 1. Definitions of primary graft dysfunction grade

\begin{tabular}{lll}
\hline & \multicolumn{1}{c}{ ISHLT PGD definition } & \multicolumn{1}{c}{$\begin{array}{c}\text { Modified ISHLT } \\
\text { PGD definition }\end{array}$} \\
\hline Grade 0 & P/F ratio $>300$ CXR clear & NA \\
Grade 1 & P/F ratio $>300$ CXR infiltrate & P/F ratio $>300$ \\
Grade 2 & P/F ratio $200-300$ & P/F ratio 200-300 \\
Grade 3 & P/F ratio $<200$ & P/F ratio $<200$ \\
Time points & T0, T12, T24, T48, T72 & T0, T12, T24, T48 \\
Worst grade & T(0-48) T(0-72) & T(0-48)
\end{tabular}

ISHLT, International Society for Heart and Lung Transplantation; PGD, primary graft dysfunction; $P / F$, partial pressure of arterial oxygen/fraction of inhaled oxygen concentration ratio; $C X R$, chest radiograph; NA, not applicable.

\section{Results}

Demographics

During the 13-year study period, we performed 402 lung transplantation procedures from cadaveric donors (Table 2); $256(64 \%)$ patients underwent single-lung transplantation (SLT), and $146(36 \%)$ underwent bilateral lung transplantation (BLT). Eight (2\%) patients (7 SLTs and 1 BLT) underwent retransplantation. The mean recipient age at the time of transplantation was $50 \pm 11$ years (range, 7-68 years), and $46 \%$ were men. The indication to undergo transplantation included chronic obstructive pulmonary disease $(61 \%)$, idiopathic pulmonary fibrosis $(12 \%)$, cystic fibrosis $(11 \%)$, primary pulmonary hypertension $(6 \%)$, and miscellaneous disorders (7\%). Patients given diagnoses of

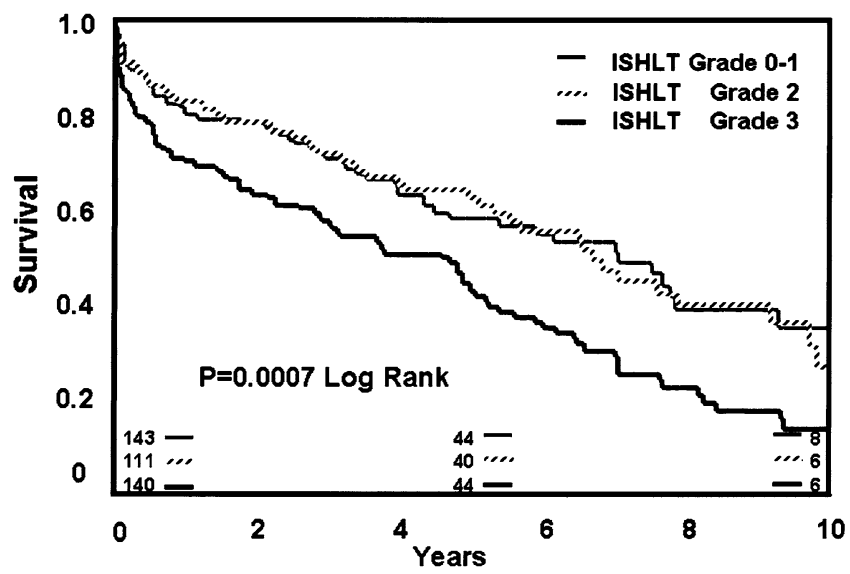

Figure 2. Long-term survival stratified by modified primary graft dysfunction grade. Kaplan-Meier actuarial survival curves are stratified by modified International Society for Heart and Lung Transplantation (ISHLT) grade. Patients with grade 3 primary graft dysfunction had a significantly reduced survival compared with those with grade 1 and grade 2 primary graft dysfunction (median survival grade 3, 4.6 years; grade 2, 6.6 years; grade 1, 7.5 years; $P=.006$, log-rank test). Grade 1 is represented in dark dray, grade 2 is represented in light gray with hatching, and grade 3 is represented in black. 
TABLE 2. Patient demographics

\begin{tabular}{lccc}
\hline & $\begin{array}{c}\text { Overall } \\
(\mathbf{n}=\mathbf{4 0 2})\end{array}$ & $\begin{array}{c}\text { SLT } \\
(\mathbf{n}=\mathbf{2 5 6})\end{array}$ & $\begin{array}{c}\text { BLT } \\
(\mathbf{n}=\mathbf{1 4 6})\end{array}$ \\
\hline Male sex (\%) & 46 & 45 & 47 \\
Age (y) & $50 \pm 11$ & $55 \pm 7$ & $41 \pm 10$ \\
Diagnosis (\%) & & & \\
$\quad$ COPD & 61 & $76^{*}$ & 37 \\
IPF & 12 & $16^{*}$ & 3 \\
CF & 11 & $<1^{*}$ & 30 \\
PPH & 6 & $<1^{*}$ & 16 \\
$\quad$ Other & 9 & $7^{*}$ & 14 \\
PA pressure (mm Hg) & & & \\
$\quad$ Cath PA (mean) & $25 \pm 11$ & $23 \pm 7 \dagger$ & $29 \pm 15$ \\
$\quad$ OR PA (mean) & $27 \pm 11$ & $25 \pm 7 \dagger$ & $30 \pm 16$ \\
Ischemic time (min) & $287 \pm 92$ & $245 \pm 62 \dagger$ & $357 \pm 90$ \\
\hline
\end{tabular}

Values are reported as percentages or as means \pm standard deviation. $S L T$, Single-lung transplantation; $B L T$, bilateral lung transplantation; $C O P D$, chronic obstructive pulmonary disease; IPF, idiopathic pulmonary fibrosis; $C F$, cystic fibrosis; $P P H$, primary pulmonary hypertension; Cath $P A$, pulmonary artery pressure measured by means of preoperative right heart catheterization; $O R P A$, pulmonary artery pressure measured by means of preimplantation Swan-Ganz catheter reading. $* \chi^{2}$ versus BLT. $\dagger t$ Test versus BLT.

chronic obstructive pulmonary disease and idiopathic pulmonary fibrosis underwent SLT significantly more often than BLT, whereas BLT was favored over SLT for other causes of end-stage lung disease. Mean allograft ischemic times were $245 \pm 62$ minutes (range, 120-428 minutes) for SLT and $357 \pm 90$ minutes (range, 194-697 minutes) for the second lung transplanted in the BLT pair (Table 2).

\section{PGD Groups and Outcome}

Grouping patients by the highest modified PGD grade (corresponding to the lowest $\mathrm{P} / \mathrm{F}$ ratio) within 48 hours of the operation yielded evenly distributed groups: 143 (38\%) patients with grade 0 to 1 PGD, $110(30 \%)$ with grade 2 PGD, and $119(32 \%)$ with grade 3 PGD. Similar numbers of patients undergoing SLTs and BLTs had 1 or more P/F measurements of less than 200 between T0 and T48 (87 SLTs, or $34 \%$, and 53 BLTs, or $37 \%$ ). The prevalence of severe PGD decreased with time: $25 \%$ of patients had grade 3 PGD at T0, $21 \%$ at $\mathrm{T} 12,17 \%$ at $\mathrm{T} 24$, and $15 \%$ at $\mathrm{T} 48$. However, the 90-day death rate associated with the occurrence of severe PGD at each time point increased with time (Figure 1). At all time points and with the worst grade end point, the development of grade 3 PGD was associated with an increased rate of perioperative death when compared with the group of patients who did not have grade 3 PDG.

The occurrence of severe PGD (modified ISHLT grade 3) within the first 48 hours after transplantation was also associated with a decreased long-term survival (Figure 2). Increasing preoperative pulmonary artery pressure, an SLT procedure, and the need for cardiopulmonary bypass during the transplantation were other independent predictors of these end points in this group of patients. ${ }^{16}$

\section{Donor Characteristics}

Reliable donor data were available on sex, age, height and weight, year of transplantation, type of procedure, days on ventilator, CMV status, mechanism of death, arterial blood gases, smoking history, ischemic times, bronchoscopic findings, and Gram stain results. All of these characteristics were examined for their bivariate associations with the development of severe PGD (Table 3). Donor age, a history of smoking of greater than 10 pack-years, and a transplantation occurring in the earlier era of the study (1992-1998) were associated with the end point at a $P$ value of less than .05 .

\section{Recipient Characteristics}

Reliable recipient data were available on type of transplantation, age, sex, height and weight, diagnosis, CMV status, pulmonary function, comorbidities, preoperative and intraoperative hemodynamics, need for cardiopulmonary bypass during the transplantation, and the preservation solution used for the procurement. All of these characteristics were examined for their bivariate associations with the development of severe PGD (Table 3). Only increasing preoperative pulmonary artery pressure and recipient diagnosis were associated with the end point at a $P$ value of less than .05 .

\section{Multivariate Model}

Donor and recipient characteristics associated with the development of severe PGD in the respective bivariate models were entered as potential risk factors in a multivariate logistic regression model. The performances of the transplantation in the earlier era of the study (1992-1998), increasing donor age, and increasing recipient preoperative pulmonary artery pressure were independently associated with the end point of severe PGD (Table 4). A graphic display of the multivariate adjusted odds of severe PGD according to donor age and preoperative pulmonary artery pressure is shown in Figure 3. There is an inflection of the donor age risk curve at approximately 30 years of age and in the pulmonary artery pressure curve at a mean pressure of $30 \mathrm{~mm} \mathrm{Hg}$.

\section{Discussion}

In our analysis of 402 lung transplant recipients at the University of Minnesota from 1992 through 2004, we have confirmed the effect of severe grade 3 PGD on short- and long-term outcomes after lung transplantation. Its occurrence at any time point within the first 48 hours after transplantation is associated with at least a 1.8-fold increase in the risk of 90-day death. In this dataset the development of severe PGD was associated with a poor early and late outcome. These data will be reported elsewhere. 
TABLE 3. Donor and recipient characteristics and their bivariate associations with grade 3 primary graft dysfunction

\begin{tabular}{|c|c|c|c|c|c|c|c|}
\hline \multirow[b]{2}{*}{ Donor characteristics } & \multicolumn{3}{|c|}{$\mathrm{T}(0-48)$} & \multirow[b]{2}{*}{ Recipient characteristics } & \multicolumn{3}{|c|}{$T(0-48)$} \\
\hline & n & grade 3 & $P$ value & & n & grade 3 & $P$ value \\
\hline Male sex & & & & Single-lung transplantation & & & \\
\hline Overall - Y & 216 & $38 \%$ & NS & Y & 256 & $35 \%$ & NS \\
\hline $\mathrm{N}$ & 177 & $32 \%$ & & $\mathrm{~N}$ & 146 & $37 \%$ & \\
\hline SLT - Y & 139 & $36 \%$ & NS & & & & \\
\hline $\mathrm{N}$ & 111 & $33 \%$ & & Era & & & \\
\hline BLT - Y & 77 & $43 \%$ & NS & 1992-1998 & 195 & $44 \%$ & .0004 \\
\hline $\mathrm{N}$ & 66 & $30 \%$ & & $1999-2004$ & 199 & $27 \%$ & \\
\hline Age (>32 y; median) & & & & PA pressure (mean) & & & \\
\hline Overall - Y & 193 & $42 \%$ & .0092 & Overall $-\leq 20$ & 131 & $31 \%$ & .006 \\
\hline $\mathrm{N}$ & 198 & $29 \%$ & & $21-29$ & 155 & $37 \%$ & \\
\hline SLT - Y & 132 & $43 \%$ & .0014 & $\geq 30$ & 96 & $42 \%$ & \\
\hline $\mathrm{N}$ & 118 & $25 \%$ & & BLT - $\leq 20$ & 40 & $35 \%$ & .0009 \\
\hline BLT - Y & 61 & $41 \%$ & NS & $21-29$ & 46 & $33 \%$ & \\
\hline \multirow[t]{2}{*}{$\mathrm{N}$} & 80 & $34 \%$ & & $\geq 30$ & 49 & $45 \%$ & \\
\hline & & & & SLT - $\leq 20$ & 91 & $29 \%$ & .019 \\
\hline Smoking - >10 pack-years & & & & $21-29$ & 109 & $39 \%$ & \\
\hline Overall - Y & 75 & $47 \%$ & 0.034 & $\geq 30$ & 47 & $38 \%$ & \\
\hline $\mathrm{N}$ & 281 & $33 \%$ & & & & & \\
\hline SLT - Y & 47 & $43 \%$ & NS & CPB & & & \\
\hline $\mathrm{N}$ & 187 & $34 \%$ & & Overall - Y & 115 & $39 \%$ & NS \\
\hline BLT - Y & 28 & $54 \%$ & .048 & $\mathrm{~N}$ & 274 & $34 \%$ & \\
\hline \multirow[t]{2}{*}{$\mathrm{N}$} & 94 & $33 \%$ & & SLT - Y & 30 & $47 \%$ & NS \\
\hline & & & & $\mathrm{N}$ & 204 & $33 \%$ & \\
\hline Traumatic brain death & & & & BLT - Y & 84 & $36 \%$ & NS \\
\hline Overall - Y & 180 & $32 \%$ & NS & $\mathrm{N}$ & 56 & $39 \%$ & \\
\hline $\mathrm{N}$ & 211 & $39 \%$ & & & & & \\
\hline SLT - Y & 113 & $30 \%$ & NS & Male sex & & & \\
\hline $\mathrm{N}$ & 137 & $39 \%$ & & Overall - Y & 180 & $32 \%$ & NS \\
\hline BLT - Y & 67 & $34 \%$ & NS & $\mathrm{N}$ & 214 & $38 \%$ & \\
\hline \multirow[t]{2}{*}{$\mathrm{N}$} & 74 & $39 \%$ & & SLT - Y & 111 & $32 \%$ & NS \\
\hline & & & & $\mathrm{N}$ & 140 & $36 \%$ & \\
\hline Positive sputum Gram stain & & & & BLT - Y & 69 & $32 \%$ & NS \\
\hline Overall - Y & 142 & $38 \%$ & NS & $\mathrm{N}$ & 74 & $42 \%$ & \\
\hline $\mathrm{N}$ & 141 & $33 \%$ & & & & & \\
\hline SLT - Y & 85 & $38 \%$ & NS & Age $>53$ y (median) & & & \\
\hline $\mathrm{N}$ & 97 & $35 \%$ & & Overall $-\mathrm{Y}$ & 197 & $35 \%$ & NS \\
\hline BLT - Y & 57 & $39 \%$ & NS & $\mathrm{N}$ & 191 & $37 \%$ & \\
\hline \multirow[t]{14}{*}{$\mathrm{N}$} & 44 & $30 \%$ & & SLT - Y & 180 & $36 \%$ & NS \\
\hline & & & & $\mathrm{N}$ & 68 & $33 \%$ & \\
\hline & & & & BLT - Y & 17 & $23 \%$ & NS \\
\hline & & & & $\mathrm{N}$ & 123 & $39 \%$ & \\
\hline & & & & Diagnosis & & & \\
\hline & & & & Overall - COPD & 243 & $31 \%$ & .016 \\
\hline & & & & IPF & 46 & $41 \%$ & \\
\hline & & & & $\mathrm{CF}$ & 44 & $43 \%$ & \\
\hline & & & & PPH & 24 & $63 \%$ & \\
\hline & & & & Other & 36 & $36 \%$ & \\
\hline & & & & SLT - COPD? Y & 191 & $34 \%$ & NS \\
\hline & & & & COPD? N & 60 & $38 \%$ & \\
\hline & & & & BLT - COPD? Y & 52 & $19 \%$ & .0005 \\
\hline & & & & COPD? N & 90 & $48 \%$ & \\
\hline
\end{tabular}

Age and recipient pulmonary artery pressure were analyzed as continuous variables. $N S$, Not significant; $S L T$, single-lung transplantation; $B L T$, bilateral lung transplantation; $P A$, pulmonary artery; $C P B$, cardiopulmonary bypass; $C O P D$, chronic obstructive pulmonary disease; IPF, idiopathic pulmonary fibrosis; $C F$, cystic fibrosis; $P P H$, primary pulmonary hypertension. 
TABLE 4. Results of multivariate logistic regression analysis of donor and recipient risk factors for primary graft dysfunction

\begin{tabular}{lccc}
\hline & Estimate \pm SE & $\begin{array}{c}\text { Estimated odds ratio } \\
\text { (95\% confidence } \\
\text { interval) }\end{array}$ & $\begin{array}{c}\boldsymbol{P} \\
\text { value }\end{array}$ \\
\hline Era (1999-2004) & $-0.32 \pm 0.12$ & $0.47(0.28-0.80)$ & .047 \\
Donor age & $-0.024 \pm 0.009$ & $1.03(1.01-1.05)$ & .006 \\
PA pressure (mean) & $-0.029 \pm 0.011$ & $1.03(1.01-1.05)$ & .014 \\
Diagnosis not COPD & $-0.21 \pm 0.12$ & & $\mathrm{NS}$ \\
Smoking $>10$ & $0.18 \pm 0.15$ & & $\mathrm{NS}$ \\
$\quad$ pack-years & & & \\
\hline
\end{tabular}

For the variables analyzed continuously, the incremental changes associated with the additive risk are per year for donor age and per millimeter of mercury for pulmonary artery pressure. $S E$, Standard error; $P A$, pulmonary artery; $C O P D$, chronic obstructive pulmonary disease.

The identification of risk factors associated with the development of severe PGD is important for several reasons. Their modification might be effective in reducing the rate of development of severe PGD. Donor-recipient matching might also be improved. Many centers have begun to use marginal or extended donors after several reports suggesting that the practice was not associated with excessive early mortality rates. ${ }^{14,18-21}$ Pierre and colleagues,${ }^{21}$ however, have recommended that caution be exercised in the widespread application of these modified donor criteria, which include donor age greater than 55 years, smoking history of longer than 20 pack-years, bronchoscopic findings of purulent secretions, the presence of infiltrates on the chest radiograph, and a $\mathrm{Po}_{2}$ of less than $300 \mathrm{~mm} \mathrm{Hg}$. In our series increasing donor age and smoking history were both associated with increased rates of PGD, although the 10 packyear smoking history breakpoint did not achieve the level of statistical significance in the multivariate model. The rate of development of grade 3 PGD within the first 48 hours for the 26 patients in the series who received lungs from donors with a greater than 20 pack-year history was $52 \%$.

The transplantation of lungs from donors older than 50 years does appear to be associated with very high risks of grade 3 PGD (Figure 3). In fact, the relationship between the odds of development of grade 3 PGD and donor age in our series is linear from about age 35 years upward, a trend very similar to that found in the analysis of other series and of ISHLT registry data with respect to longer-term mortality. ${ }^{3}$ The most favorable recipient outcomes seem to be associated with donors between 20 and 30 years of age.

Our program has been conservative with respect to our acceptance of marginal donors by other criteria outlined by Pierre and colleagues. ${ }^{21}$ Very few donors had arterial blood gas $\mathrm{Po}_{2}$ values of less than $300 \mathrm{~mm} \mathrm{Hg}$, only $11 \%$ of donor lungs had an infiltrate on the chest radiograph, and only $6 \%$ had significant purulent bronchoscopic secretions. None of

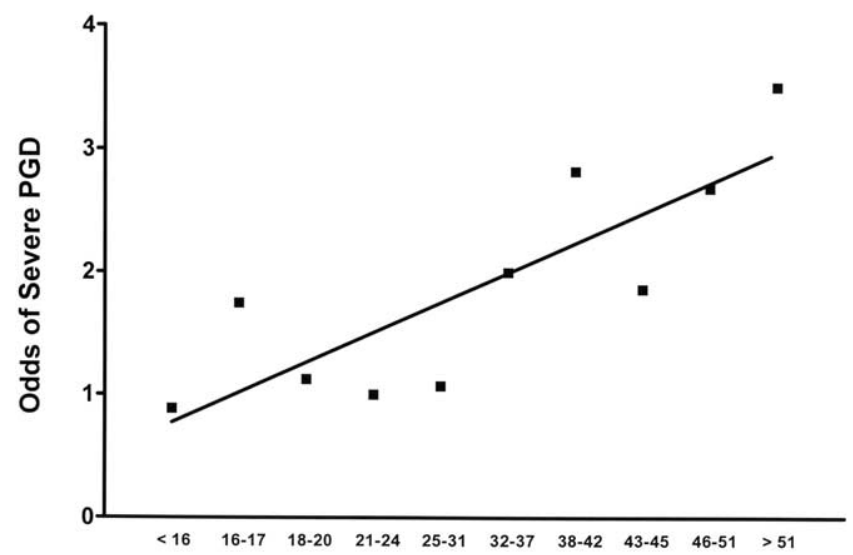

A

Donor Age

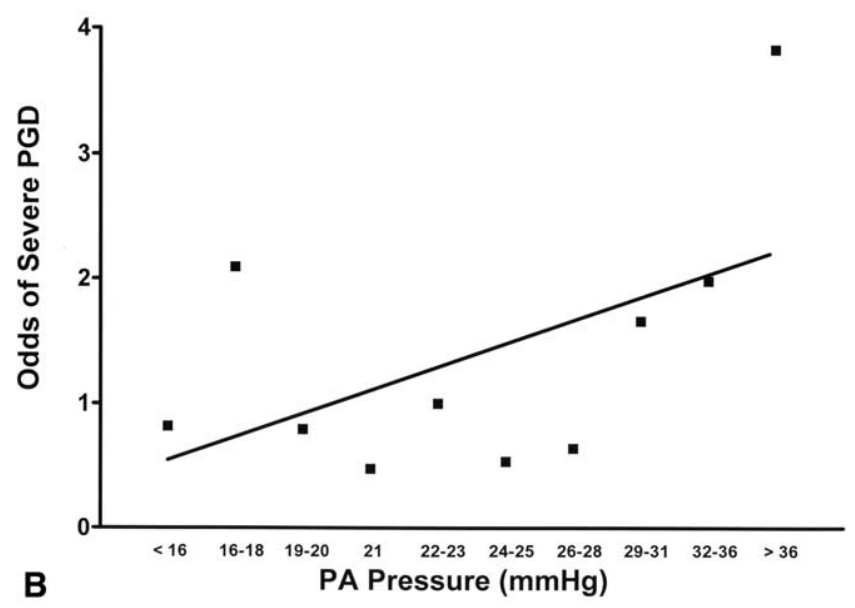

Figure 3. Adjusted odds of severe primary graft dysfunction (PGD). A, Multivariate adjusted odds of PGD according to donor age. Individual points represent the mean odds of groups of 40 patients. The first data grouping was used as the reference. B, Multivariate adjusted odds of PGD according to pulmonary artery $(P A)$ pressure. Individual points represent the mean odds of groups of $\mathbf{4 0}$ patients. The first data grouping was used as the reference.

these characteristics were significantly associated with the development of grade 3 PGD in our series. A positive Gram stain result was reported in 143 (49\%) of 289 donors for whom data were available. There was no difference in the rate of development of grade 3 PGD among recipients receiving lungs from a donor with a positive or a negative Gram stain result, although the vast majority of these patients had only $1+$ gram-positive organisms identified on the test.

Our analysis has several limitations. First, we choose to analyze only one of many possible end points that reflect the development of severe PGD in a patient after a transplantation. Other choices incorporating the 72-hour time mea- 
surements or the associated chest radiographic findings might have additional discriminate validity with respect to early or longer-term patient outcomes. The optimal indicator of PGD will likely be identified once the working group definition is published and transplant centers have had the opportunity to validate the predictive power of its various components. Because severe PGD occurs with a greater frequency than death and is associated with a poor shortand long-term outcome, the analysis of this end point in clinical care and in clinical trials is warranted. We believe that because severe PGD is associated with a poor outcome, the analysis of risks of severe PGD, rather than mortality, would be more predictive.

In summary, the development of severe (modified ISHLT grade 3) PGD is associated with a high operative mortality and a poor long-term survival. The incidence of severe PGD in our program has decreased over time. In a multivariate analysis, additional risk factors for grade 3 PGD development within the first 48 hours after transplantation (one measure of PGD) are (1) an increased preoperative pulmonary artery pressure and (2) an increasing donor age. Identification of at-risk patients and selective management through altered strategies of ventilation to reduce airway pressure, as in ARDS, or with $\beta$-blockade to limit perfusion, with pharmacologic agents to reduce ischemiareperfusion injury, or with extracorporeal membrane oxygenation to allow the lungs a period of low-perfusion recovery might ultimately improve the outcomes of patients undergoing pulmonary transplantation..$^{9,12}$

\section{References}

1. Christie JD, Bavaria JE, Palevsky HI, Litzky L, Blumenthal NP, Kaiser LR, et al. Primary graft failure following lung transplantation. Chest. 1998;114:51-60.

2. Christie JD, Sager JS, Kimmel SE, Ahya VN, Gaughan C, Blumenthal $\mathrm{NP}$, et al. Impact of primary graft failure on outcomes following lung transplantation. Chest. 2005;127:161-5.

3. Christie JD, Kotloff RM, Pochettino A, Arcasoy SM, Rosengard BR, Landis JR, et al. Clinical risk factors for primary graft failure following lung transplantation. Chest. 2003;124:1232-41.

4. Bernard GR, Artigas A, Brigham KL, Carlet J, Falke K, Hudson L, et al. The American-European Consensus Conference on ARDS. Definitions, mechanisms, relevant outcomes, and clinical trial coordination. Am J Respir Crit Care Med. 1994;149:818-24.

5. Sekine Y, Waddell TK, Matte-Martyn A, Pierre AF, de Perrot M, Fischer S, et al. Risk quantification of early outcome after lung transplantation: donor, recipient, operative, and post-transplant parameters. J Heart Lung Transplant. 2004;23:96-104.

6. Avlonitis VS, Krause A, Luzzi L, Powell H, Phillips JA, Corris PA, et al. Bacterial colonization of the donor lower airways is a predictor of poor outcome in lung transplantation. Eur J Cardiothorac Surg. 2003; 24:601-7.

7. Smits JM, Melman S, Mertens BJ, Laufer G, Persijn GG, Van Raemdonck D, et al. The Eurotransplant Study on Twin Lung Transplants (ESOTWIN): 90 paired single-lung transplants from the same donor. Transplantation. 2003;76:1604-8.

8. Ardehali A, Laks H, Levine M, Shpiner R, Ross D, Watson LD, et al. A prospective trial of inhaled nitric oxide in clinical lung transplantation. Transplantation. 2001;72:112-5.
9. Fisher AJ, Wardle J, Dark JH, Corris PA. Non-immune acute graft injury after lung transplantation and the risk of subsequent bronchiolitis obliterans syndrome (BOS). J Heart Lung Transplant. 2002;21: 1206-12.

10. Struber M, Wilhelmi M, Harringer W, Niedermeyer J, Anssar M, Kunsebeck A, et al. Flush perfusion with low potassium dextran solution improves early graft function in clinical lung transplantation. Eur J Cardiothorac Surg. 2001;19:190-4.

11. Westerlind A, Nilsson F, Ricksten SE. The use of continuous positive airway pressure by face mask and thoracic epidural analgesia after lung transplantation. Gothenburg Lung Transplant Group. J Cardiothorac Vasc Anesth. 1999;13:249-52.

12. Dahlberg PS, Prekker ME, Herrington CS, Hertz MI, Park SJ. Medium-term results of extracorporeal membrane oxygenation for severe acute lung injury after lung transplantation. J Heart Lung Transplant. 2004;23:979-84.

13. Dahlberg PS, Prekker ME, Hertz M, Thompson DJ, Park SJ. Recent trends in lung transplantation: the University of Minnesota experience. Clin Transplant. 2002;18:243-52.

14. Shumway SJ, Hertz MI, Petty MG, Bolman RM 3rd. Liberalization of donor criteria in lung and heart-lung transplantation. Ann Thorac Surg. 1994;57:92-5.

15. Christie JD, Ahya VN, Sager JS, Pocchetina E, DeMissis L, Zhou L, et al. ISHLT PGD grade predicts differential mortality following lung transplantation. J Heart Lung Transplant. 2005;24(suppl):S71-2.

16. Prekker ME, Nath DS, Johnson AC, Walker AR, Hertz MI, Dahlberg PS. Validation of the proposed ISHLT grading system for primary graft dysfunction following lung transplantation. J Heart Lung Transplant. 2005;24(suppl):S72.

17. Ananth CV, Kleinbaum DG. Regression models for ordinal responses: a review of methods and applications. Int J Epidemiol. 1997;26:1323-33.

18. Sundaresan S, Semenkovich J, Ochoa L, Richardson G, Trulock EP, Cooper JD, et al. Successful outcome of lung transplantation is not compromised by the use of marginal donor lungs. J Thorac Cardiovasc Surg. 1995;109:1075-9.

19. Sundaresan S, Trachiotis GD, Aoe M, Patterson GA, Cooper JD. Donor lung procurement: assessment and operative technique. Ann Thorac Surg. 1993;56:1409-13.

20. Straznicka M, Follette DM, Eisner MD, Roberts PF, Menza RL, Babcock WD. Aggressive management of lung donors classified as unacceptable: excellent recipient survival one year after transplantation. J Thorac Cardiovasc Surg. 2002;124:250-8.

21. Pierre AF, Sekine Y, Hutcheon MA, Waddell TK, Keshavjee SH. Marginal donor lungs: a reassessment. J Thorac Cardiovasc Surg. 2002;123: 421-7.

\section{Discussion}

Dr G. Alexander Patterson (St Louis, Mo). Primary graft dysfunction (PGD), or what we used to refer to by a number of other terms, such as reperfusion injury or reimplantation pulmonary edema, is a common problem in lung transplantation. This has been demonstrated to us once again today. It has been the focus of more than 2 decades of research and clinical investigation. The transplantation community has learned a lot in recent years regarding the molecular pathogenesis of this problem, and we have developed some very effective strategies to treat it and to lessen its likelihood.

The International Society for Heart and Lung Transplantation Pulmonary Council Working Group, under the direction of Dirk Van Raemdonck and Jason Christie, have developed and will soon publish in the Journal of Heart and Lung Transplantation a standardized definition of PGD, which was referred to here today. This report by the Minnesota group is an effort to use the new definition to identify risk factors for the development of PGD.

I have a couple of questions. I do not know that you referred to this specifically in your presentation, but in the article you elimi- 
nated donor radiograph or graft radiograph review. There is no comment in your article about radiographic infiltrates. Can you explain why that is?

Dr Whitson. Well, that is used in the ISHLT criteria. In our analysis, or at least when the data were initially collected, the chest radiographic reports were not initially looked at. We reviewed a small number of patients who had a $\mathrm{P} / \mathrm{F}$ ratio that was greater than 300 and looked at their infiltrates, and looking at the outcomes for their long-term survival, whether it was by grade 0 or grade 1 , it did not seem to have a difference, and therefore we lumped them together, partly because those data had not been collected, looking back at it. When we looked at the survival, both short-term and long-term survival, their stratification is on whether they did or did not have grade 3 PGD, and the chest radiograph was not included in the grade 3 definition. Therefore we did not go back and pull those.

Dr Patterson. You have demonstrated quite clearly that the incidence of reperfusion injury or PGD is decreasing over time. There is a clear difference in your own experience with respect to its incidence in the former era and the more recent era. Surely that has to be a surrogate marker for technical changes. Can you make any specific comments about your perfusion strategy or your flush strategy, your inflation strategy, and how that has changed in those 2 intervals of time?

Dr Whitson. Over those 13 years, we have essentially kept the technical aspects the same. We have used antegrade perfusion. In 2001, we switched from Euro-Collins to Perfadex for the perfusion solution.

Dr Patterson. Do you not use retrograde flush in your preservation strategy?

Dr Whitson. No.

Dr Patterson. The other question I have-and I am not a statistician-but you have examined many possible risk factors, both donor and recipient risk factors. Close to 30 separate risk factors were studied. It seems to me that by chance alone you are going to identify something that is significant and predictive. Specifically with regard to cardiopulmonary bypass, it seems to me that your use of cardiopulmonary bypass is really quite high, certainly higher than it is in our own institution, particularly because you use a single-lung transplantation as an operative strategy in quite a few, in almost half of your patients or perhaps more, and therefore it is not clear to me whether cardiopulmonary bypass is actually a risk factor or whether it is a result. In our program we use cardiopulmonary bypass most frequently when we have failure of the initial graft, and therefore we have already got graft dysfunction before bypass is used. Can you comment?

Dr Whitson. You are correct that the more risk factors that are analyzed the more likely it is that a type I error will be made. We only analyzed risk factors that made sense clinically, and reasonable arguments can be made for why each of those significant in the multivariate analysis could cause early graft dysfunction. Bypass was used in $12 \%$ of single lung procedures and in $60 \%$ of bilateral single transplants. The usual indications were significant adhesions or pulmonary hypertension and to some extent surgeon preference, especially in the bilateral transplants.

Dr R. Duane Davis, Jr (Durham, NC). I want to follow up a little bit on what Alec had asked you. Does your group have a strategy for the reperfusion of the recipient, or is it just kind of unclamp and go?

Dr Whitson. Thank you, Dr Davis. We avoid using 100\% $\mathrm{FIO}_{2}$ and high inspiratory tidal volumes when reinflating the lung. More recently, we have used beta blockade in selective circumstances to limit unnecessarily high cardiac outputs. If patients are on cardiopulmonary bypass, we let the heart fill slowly and cut back the flow rate over a 10-minute period. As for the clamps, they are released gradually over a 5- to 10minute period. 